\title{
PLANO DE VIDA: PROPOSTA DE UM PROGRAMA DE PREPARAÇÃO PARA A REFORMA
}

\author{
LIFE PLAN: PROPOSAL FOR A PROGRAM OF PREPARATION FOR REFORM
}

\author{
Emerson Wagner Mainardes \\ Universidade da Beira Interior - Covilhã/Portugal \\ Oliva Martins \\ Universidade da Beira Interior - Covilhã/Portugal \\ Maria Jose Silva \\ Universidade da Beira Interior - Covilhã/Portugal
}

\section{RESUMO}

Nos momentos mais difíceis, as pessoas, de uma forma geral, sentem a falta de um planeamento da sua vida pessoal e profissional. 0 objectivo deste estudo foi propor um "plano de vida" ou um "guia de planeamento pessoal", baseado nos tradicionais modelos de "planos de negócios", que vise uma reforma tranquila. No final deste estudo, pretendeu-se fornecer uma estrutura de modelo que permita o desenvolvimento de um guia prático para a construção de planeamento pessoal ao longo da vida do indivíduo, bem como oferecer uma estrutura básica para o desenvolvimento de softwares que facilitem a construção deste planeamento da vida das pessoas, pois acredita-se que uma vida planeada oferece melhores condições para ter-se uma vida com mais qualidade, antes e depois da reforma.

Palavras-chave: Plano de negócios. Reforma. Plano de vida. Planejamento pessoal.

\begin{abstract}
Individuals generally feel the need for a personal and professional life planning at the most difficult moments. This study aims to propose a "life plan", which means a personal planning program regarding a peaceful retirement, based on the models of traditional business plans. By the end of this study, a model shall be supplied. This model will allow the development of a practical guide for the creation of personal plans throughout the life of the individuals, providing as well a basic structure for the development of software programs that enable the creation of these personal life plans. The measures concerning the creation of life plans are based on the belief that a planned life offers conditions to people that allow them to live with a higher standard of quality in a period that proves to be critical for many people: retirement.
\end{abstract}

Keywords: Business plan. Retirement. Life plan. Personal planning. 


\section{INTRODUÇÃO}

Genericamente é reconhecida, tanto na literatura, como no mercado, que a elaboração de um business plan (plano de negócios) contribui positivamente para o bom desempenho tanto das organizações nascentes, como para as organizações estabelecidas (HORMOZI et al., 2002). Um plano de negócios orienta as organizações no curto, médio e longo prazo, ao definir objectivos, estratégias, planos de acção, de toda a organização (COLLIER, 2004).

Se planear é tão importante para as organizações, questiona-se: Será que as pessoas também precisam de fazer um planeamento pessoal? Será que as pessoas deveriam possuir o seu próprio "plano de negócios"? Qual a importância de desenvolver um planeamento? 0 que mudaria na vida das pessoas? Qual a diferença entre os resultados de quem planeou a vida e quem não pensa no amanhã? Foram estas perguntas que motivaram a realização deste estudo.

Nos momentos mais difíceis, as pessoas, de uma forma geral, sentem a falta de um planeamento da sua vida pessoal e profissional. Um destes momentos críticos é quando o indivíduo se reforma (SIMÕES, 2007). Uma reforma não planeada adequadamente pode ser dramática. A falta de recursos financeiros aliada ao excesso de tempo sem ocupação, conduzem à perda de sentido para a vida, criando um sentimento de vazio e exclusão social (RODRIGUES et al, 2005). Se for desenvolvido um planeamento antes da reforma, a prever o futuro, torna-se possível estabelecer objectivos, definir direcções, e potencializar o percurso de vida até a reforma de forma muito mais tranquila. Entretanto o mais usual é não desenvolver-se um plano pessoal estruturado, que contemple toda a vida da pessoa. Questiona-se então como é possível planear a "vida após a reforma" sem grandes preocupações? A questão financeira é a única que importa?

Parte-se do princípio que o planeamento para a reforma não deve ser somente financeiro, mas envolver todos os aspectos pessoais e profissionais do indivíduo. Desta forma, o objectivo deste estudo foi propor um "plano de vida" ou um "guia de planeamento pessoal", baseado nos tradicionais modelos de "planos de negócios", que vise uma reforma tranquila. 0 conceito de plano de negócio está relacionado à descrição do negócio através de um documento único que integra os recursos e as diversas áreas do empreendimento, determinando seus objectivos, políticas e estratégias de governação (ABRAMS, 1994).

Para atingir este objectivo geral, definiu-se como objectivos específicos:

(a) Recomendar acções estratégicas para o plano pessoal e profissional do indivíduo;

(b) Indicar os caminhos para um marketing eficaz, tanto no plano pessoal quanto no profissional;

(c) Sugerir práticas para o desenvolvimento pessoal do indivíduo;

(d) Estabelecer acções que contribuam para o desenvolvimento profissional de uma pessoa;

(e) Identificar questões legais que envolvam o indivíduo antes e depois da reforma;

(f) Propor formas de gerir as finanças pessoais e os investimentos.

A contribuição deste estudo abrange não só os indivíduos que se preocupam, ou deveriam preocupar-se com a reforma, mas também as entidades que influenciam, ou são influenciadas, pela reforma dos cidadãos (empresas, governos, bancos, seguradoras, entre outras). No final deste estudo, pretendeu-se fornecer uma estrutura de modelo que permita 0 
desenvolvimento de um guia prático para a construção de planeamento pessoal ao longo da vida do indivíduo, bem como oferecer uma estrutura básica para o desenvolvimento de softwares que facilitem a construção deste planeamento da vida das pessoas, pois acredita-se que uma vida planeada oferece melhores condições para ter-se uma vida com mais qualidade, antes e depois da reforma.

\section{VIDA ANTES E PÓS A REFORMA}

Definir o verbo trabalhar é difícil e complexo pois envolve um conceito com diferentes significados entre os indivíduos: envolve a interacção entre actividades, responsabilidades, motivações e retribuições em determinada situação (MARTINEZ; PARAGUAY; LATORRE, 2004). É ainda uma forma de posicionar-se, pessoal, social e profissionalmente (LUNNARDI FILHO, 1997; ALBERTO, 2000).

A partir do significado do trabalho, torna-se fácil compreender por quê a reforma costuma ser um dos momentos mais críticos na vida de qualquer pessoa. De uma hora para a outra, o indivíduo passa a ter muito tempo sem ocupação. Sem saber o que fazer e fora do mercado de trabalho, o que existe é um sentimento de ser menos útil; e a maioria dos casos, têm o seu rendimento muito reduzido. Na investigação realizada por Zanelli e Silva (1996) identificaram um sentimento de insegurança quanto à reforma. Martín-Baró (1985) sintetizou o processo de socialização como um processo histórico de desenvolvimento da própria identidade, pessoal e social, enquanto que a reforma é uma ruptura brusca deste processo natural de relacionamentos. Por todas estas razões muitos indivíduos adiam ao máximo este momento da reforma.

Aliado a isto, percebe-se uma falta generalizada de planeamento pessoal. A falta de um "plano de vida" é sentida nos momentos difíceis de uma pessoa, como a descoberta de uma doença inesperada, ou a perda de um emprego, ou por um problema com a casa ou carro, ou na fase de transição da reforma, quando o indivíduo deixa o mercado de trabalho.

Planear no meio empresarial e organizacional têm-se mostrado fundamental, não somente para garantir o futuro das empresas, apesar das dificuldades existentes para definir que caminho deve-se seguir para obter sucesso mas, também, para a identificação de forças e fraquezas e o consequente controlo dos riscos (HORMOZI et al., 2002).

$\mathrm{Na}$ vida pessoal planear é mais difícil e a reforma normalmente acontece por imposição do tempo. A dificuldade é cultural: não há por hábito o indivíduo traçar seus próprios objectivos pessoais, ou desenvolver um plano estruturado que delineie os passos a serem seguidos para atingir os objectivos pretendidos, desde a aquisição de um carro novo, uma casa, uma viagem de sonho, até uma reforma mais segura e tranquila. Definir uma meta é o primeiro passo, mas não se alcança uma meta sem ter um bom plano (FRANKLIN, 2008).

$\mathrm{Na}$ actual sociedade de consumo há um estímulo frequente para aquisições de bens e serviços durante a vida de trabalho, com gastos menos necessários e que são realizados sem preocupação com a vida futura. Em muitos momentos vê-se pessoas a utilizar seus recursos de reserva para coisas desnecessárias, sem pensar em situações de contingências que podem vir a ocorrer. Isto demonstra a importância de um plano de vida para conduzir seus actos e atitudes, pois os gastos excessivos acabam por influenciar o futuro da reforma.

As preocupações aumentam quando se constata um crescimento da expectativa de vida dos seres humanos da actualidade (gráficos 1 e 2). Hoje é possível uma pessoa viver mais anos como reformado do que como trabalhador e, assim, custar mais à sociedade do que aquilo que 
efectivamente contribuiu.

Gráfico 1: População com idade 65 anos (\% do Total) Gráfico 2: Esperança de Vida
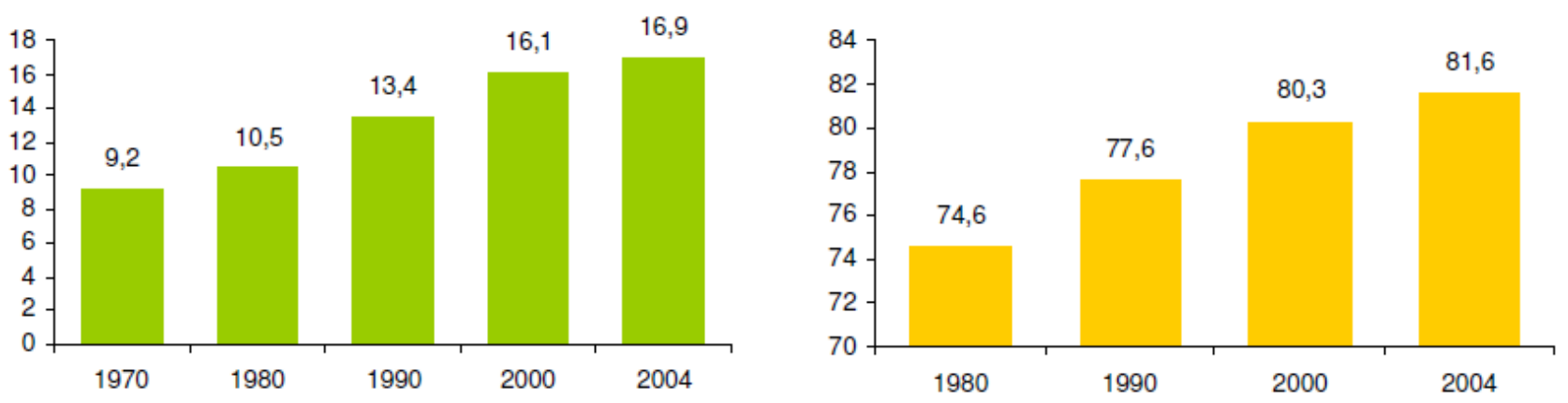

Fonte: Banco Mundial (2006)

Para dar uma ideia desta diferença, há que considerar dois aspectos: primeiro o valor de contribuição do trabalhador encontra-se em média à volta dos $11 \%$ sobre o salário (fora a parte da empresa); um trabalhador, tendo iniciado cedo a sua vida economicamente activa, e que contribuiu por 30 ou 35 anos, pode ter o direito à reforma quando tiver 50 a 55 anos; por outro lado, a expectativa de vida encontra-se à volta dos 81 anos (gráfico 2); logo aumenta o período de reforma quando a expectativa de vida cresce. Nestes casos, vive-se mais tempo enquanto reformados do que os anos de contribuição. Esta é a base das preocupações: idades e valores diminutos da reforma eventualmente indicam que o indivíduo precisa voltar a trabalhar para completar os rendimentos que recebe, e o merecido descanso da reforma, fica em segundo plano.

Em resumo, para ter-se uma reforma com qualidade de vida igual ou superior ao que tinha quando estava activo economicamente, há que pensar e planear a reforma, definir objectivos, meios e recursos para atingi-los, inclusivamente, preparar planos de contingência para as situações inesperadas, da mesma forma que as organizações. Há que desenvolver o seu plano de vida.

\section{PLANO DE NEGÓCIOS}

Apesar de muitos negócios de sucesso serem conhecidos por surgirem sem nenhum planeamento inicial, o facto é que inúmeras empresas falharam por não terem planeado adequadamente a sua continuidade (SHARMA, 1999). Segundo Rule (1999), o plano de negócios mostra-se como um instrumento necessário para orientar o empreendedor na difícil tarefa de lançar um novo negócio ou mesmo conduzir um negócio já existente. É uma ferramenta dinâmica e por isso deve ser sempre reavaliada (ARKEBAUER, 1994).

Um plano de negócios não garante a sobrevivência de um empreendimento, porém opera seu risco e evita problemas (HORMOZI et al., 2002), pois o conhecimento obtido em sua elaboração, com informações recolhidas de forma sistemática, permite ao empreendedor conhecer melhor os factores externos (políticos, económicos, sociais, mercado, concorrência, fornecedores, entre outros) e internos (stakeholders, recursos humanos, tecnologias, entre outros) que influenciam o seu negócio. Este conjunto de informações auxilia nas decisões que deverão ser tomadas pelo empreendedor, com vistas a sustentar e perpetuar o seu empreendimento. 
Para desenvolver um plano de negócios como uma ferramenta eficaz, os gestores da organização precisam dividi-lo em módulos; por mais simples que seja, uma organização é sempre complexa, sendo mais eficaz a análise em separado das diversas áreas envolvidas.

Apesar dos aspectos financeiros serem os de maior interesse em qualquer plano de negócios, cabe ressaltar que ele é a última parte do plano, por ser reflexo das decisões tomadas nos outros módulos (estratégias, seguida das políticas de marketing, recursos humanos e operações, questões legais, etc.). Portanto, o esforço é maior para desenvolver os módulos anteriores ao planeamento financeiro, sendo este o último a ser preparado, e que deve contemplar todas as decisões tomadas nos módulos anteriores. Se o resultado financeiro ficar abaixo do esperado, um novo ajuste deverá ser contemplado nos módulos já desenvolvidos. É ma revisão necessária para se ter um plano de negócios condizente com a realidade (RULE, 1999).

Um bom plano de negócios deve conter a compreensão das necessidades, análise das potencialidades (forças) e deficiências (fraquezas) e das possíveis estratégias para aproveitar as oportunidades e superar as ameaças de um empreendimento, prevendo possíveis problemas e possibilitando uma visão ampla de todo o negócio (WARD, 2003). A decisão do empreendedor, se bem idealizada, baseada num planeamento eficaz, traduz-se num diferencial competitivo perante seus concorrentes (vantagem competitiva). Para Longenecker, Moore e Petry (1997), um plano de negócios bem idealizado necessita:

- Centrar todas as informações necessárias para iniciar ou continuar o empreendimento, num único documento (plano), visando minimizar erros, incertezas, surpresas e problemas;

- Obrigar o empreendedor a realizar uma avaliação do potencial do negócio (perspectivas de resultados, crescimento e lucro), além de suas necessidades financeiras e operacionais;

- Contribuir para a elaboração de uma estratégia competitiva baseada em estudos do mercado;

- Auxiliar na captação de recursos que viabilizem o objecto do plano (proprietários, investidores, instituições financeiras, etc.);

- Ajudar na organização administrativa da empresa, principalmente quanto ao recrutamento e selecção dos empregados, e distribuição de funções entre as várias áreas funcionais da empresa;

- Servir como um elemento orientador do negócio.

O planeamento mostra-se como indispensável para o êxito da gestão de qualquer empreendimento. Um empreendedor consciente da sua importância, utiliza-o porque é um mecanismo que auxilia a criação (inclusivamente ajuda na busca por investidores), a expansão ou a ampliação do empreendimento (HORMOZI et al., 2002).

\section{PLANO DE VIDA}

A maioria dos seres humanos procura sua independência intelectual e financeira (SIMIÃO, 2003). Em grande parte dos casos, atingir esta independência exige planeamento (um bom plano de vida, que contemple não somente os anos antes da reforma, mas todo o período de vida, inclusivamente a pós-reforma do indivíduo) e muito investimento, de tempo para 
acompanhar, e de dinheiro para as possíveis contingências.

Em analogia ao plano de negócios, o plano de vida estabelece, durante os anos da vida economicamente activa, meios que possibilitem ter uma reforma com qualidade e segurança.

Para formalizar o plano a ser seguido é preciso: definir estratégias, possuir um plano de marketing pessoal, outro de desenvolvimento pessoal e profissional, ter conhecimento das questões legais que envolvem cada cidadão e, por fim, desenvolver um plano financeiro e de investimentos (GIACOBBO; REIS; FRANCISCO, 2004). A formalização do plano de vida não garante o sucesso na vida da pessoa, mas tem um papel muito importante na orientação das acções do indivíduo em cada momento de sua vida, em especial nos momentos mais difíceis.

Um plano de vida abrange especificidades únicas de cada pessoa pois depende de seus objectivos, recursos e capacidades para atingi-los; por esta razão, um plano de vida, à partida, diferencia-a das demais pessoas. Para Simião (2003), no campo pessoal, será um indivíduo mais seguro de si, mais equilibrado emocionalmente, mais preparado para encarar os dissabores da vida. Já no campo profissional, terá maior probabilidade de prosperidade e de aproveitar as oportunidades que surgirão naturalmente, como empregado ou proprietário de uma organização. Em suma, um plano de vida bem elaborado e voltado para os objectivos perseguidos pode desenvolvê-lo mais, diferenciando-o na luta pela sobrevivência do dia-a-dia.

Mas planos de vida ainda são excepções. No contexto geral, as pessoas possuem seus objectivos definidos como "sonhos de vida", muitas vezes, sinónimos de inatingíveis, simplesmente porque pouco realizam em termos de criar oportunidades de desenvolver seus pontos fortes e superar suas fraquezas no curto, médio e, principalmente, no longo prazo. Sem metas estabelecidas torna-se difícil obter resultados eficazes, perdendo tempo na resolução dos problemas que ocorrem, sem nenhuma preparação para resolvê-los. Um bom plano poderia contemplar a solução de situações de contingência (como a falta de dinheiro ou perda de um emprego).

Para serem eficazes, os planos de vida devem prever no longo prazo, e espera-se que os resultados também demorem para surtir efeito; a maior dificuldade é a postura imediatista das pessoas, que esquece os longos anos que a vida pode durar; no lugar de preocupação com futuro, encontra-se decisões simplificadas que retardam a real solução dos problemas.

Tendo consciência de que a maioria das pessoas não desenvolve seu plano de vida, instituições voltadas para a reforma dos cidadãos podem contribuir de forma significativa para minimizar o desgaste de quem ainda não se preparou para o fim da sua vida economicamente activa.

Organizações que oferecem previdência privada corroboram para manter as actuais remunerações no momento da reforma e, consequentemente, a qualidade de vida, através da oferta de seguros privados. Ainda assim, são poucas as pessoas que contratam este tipo de seguro. Menos ainda são as pessoas que conseguem cumprir a totalidade do seguro contratado.

Em momentos de crise ou mera dificuldade, a tendência é a retirada dos depósitos realizados ou a suspensão das contribuições.

Estas empresas já perceberam que não basta oferecer o serviço de gestão financeira; é necessário ajudar cada segurado para que o mesmo cumpra com seus compromissos até a reforma. Uma alternativa é auxiliar os segurados nas questões que envolvam o planeamento 
futuro de cada pessoa. Tem-se observado algumas acções neste sentido, principalmente associadas aos bancos que oferecem previdência privada. Porém estas acções nem sempre atingem seu objectivo.

Analisando-se as possíveis causas de ineficácia, levanta-se a hipótese de serem acções incompletas, voltadas apenas para as questões financeiras. Como dito anteriormente, um plano de vida ou de negócios envolve muito mais do que um plano financeiro. Aliás, um plano financeiro é simplesmente a consequência do restante do planeamento.

Surge assim a principal questão: Como realizar um plano de vida estruturado e formalizado, que auxilie as pessoas no processo de tomada de decisão pessoal?

E que responda questões como: Quando trocar de emprego? Que competências e habilidades buscar? O que fazer quando acontece uma situação inesperada? Quando contratar um financiamento? Que documentos guardar para evitar dissabores no momento da reforma?

Estas questões devem ser previamente pensadas no momento do desenvolvimento do plano de vida. Um plano deve fornecer uma visão clara dos objectivos pretendidos e dos meios e recursos para atingi-los (ARKEBAUER, 1994). Deve ainda direccionar os esforços pessoais para o que realmente interessa; disciplinar o pensamento da pessoa e de seus familiares; integrar os esforços de todos os envolvidos; reduzir riscos; oferecer planos de contingência para situações inesperadas; apresentar oportunidades e ameaças ao indivíduo, tanto pessoal quanto profissionalmente.

Para Floodgate e Nixon (1994), um indivíduo que desenvolve um plano de vida focaliza suas necessidades, direcciona seus recursos, aproveita oportunidades e dá passos mais seguros. Porém, o plano precisa ser estruturado e formalizado.

Na literatura há poucos estudos voltados para planos de vida estruturados; a fim de desenvolver este estudo, fez-se uma analogia ao plano de negócios de uma empresa.

Entretanto, não basta ter o plano no papel. É necessária uma mudança na cultura das pessoas, pois o papel nada ajudará se não for seguido, controlado e até modificado quando necessário, pois o plano prevê um prazo longo mas não consegue suprimir as mudanças de contexto que acontecem no decorrer da sua execução. 0 principal beneficiário do plano deve manter o compromisso (por mais difícil que seja), superar a inércia e a apatia, e partir com disposição para seus objectivos pretendidos (TAMKIN, 1996). Isto depende de cada um.

Mas a intenção de ter um plano de vida estruturado e formalizado não é suficiente. Ainda há imensos desafios. Para Higson e Wilson (1995), a maioria das pessoas não sabe como desenvolver um planeamento pessoal. Há dificuldade em reconhecer seu próprio potencial e fraqueza. Neste sentido, as organizações que oferecem previdência privada pode ter um papel crucial ao actuar como consultoras, e podem ajudar a definir metas, e orientar como organizar e planear seu futuro.

Além disto, o plano de vida deve ser, conforme esclareceu Bennett (2006), um documento completo, que detalhe as intenções da pessoa e apresente acções com respeito ao próprio desenvolvimento do indivíduo. Para Taylor e Edge (1997), deve possuir dimensões semelhantes a um plano de negócios, considerando os impactos potenciais de cada possível situação que possa vir a ocorrer, prevendo eventos futuros e suas possíveis soluções (como a perda do emprego, por exemplo). Seguindo esta linha de raciocínio, um plano de vida deve tratar de: estratégias pessoais; marketing; desenvolvimento pessoal e profissional; 
enquadramento legal; finanças pessoais e investimentos. Esta é a sequência do plano de vida proposto aqui.

\section{ESTRATÉGIAS PESSOAIS}

A estratégia foi criada pelos gregos, que deram uma conotação militar ao conceito. 0 termo origina-se do grego "strategos", sendo traduzida como "general no comando de tropas" ou "a arte do general" ou ainda "plano de destruição de inimigos através do efectivo uso de recursos" (BRACKER, 1980; STEINER; MINER, 1981; LEITÃO, 1995). Este termo já trazia a ideia de objectivo a ser alcançado e dos planos de acção a serem realizados em diversos cenários, de acordo com o comportamento do inimigo (SCHNAARS, 1991).

Ao voltar-se para a gestão, o termo evoluiu, criou credibilidade junto aos académicos e originou a disciplina da gestão estratégica, com conteúdos, conceitos e razões práticas da gestão das organizações (CAMARGOS; DIAS, 2003). Actualmente, é muito utilizada pelas organizações.

Conforme McCarthy, Minichello e Curran (1975), a estratégia pode ser definida como uma análise do ambiente envolvente, e selecção de alternativas que orientam os recursos para atingir objectivos da organização, conforme a viabilidade, o risco e a possibilidade de lucro que cada alternativa oferece. Esta é somente uma das inúmeras definições de estratégia (MAINARDES; FERREIRA; ANDRADE, 2009), sendo esta a definição que mais se aproxima do objectivo proposto neste trabalho.

Se para sobreviver, as empresas precisam definir uma estratégia, parece lógico considerar que cada indivíduo, para se manter no mercado de trabalho e prosperar, também deva estabelecer suas estratégias pessoais, algo raramente lembrado na literatura. Muito se discute a respeito das estratégias nas organizações, mas pouco se refere às estratégias individuais, de crescimento e desenvolvimento pessoal.

Desta forma, a proposta presente consiste em estabelecer uma estratégia própria que acompanhe o indivíduo, antes de qualquer decisão sobre o seu futuro. Ou seja, além de definir seus objectivos, é preciso identificar qual a actual situação, que acções desenvolver e pensar nos meios e recursos para atingi-lo. 0 conceito envolto neste estudo identifica a análise do ambiente como parte da estratégia (MINTZBERG, 1987). E relacionou à estratégia, a atitude pró-activa, por parte do estrategista, aos movimentos do ambiente.

Uma forma de análise do ambiente para elaboração estratégica começa com um diagnóstico. 0 diagnóstico é o estabelecimento do ponto de situação, da compreensão da situação actual. A realização deste diagnóstico deve ser feita da forma mais honesta possível, e envolver a análise das forças e fraquezas do indivíduo, pessoal e profissional. Em um segundo momento, e de acordo com as forças e fraquezas identificadas, procurar encontrar oportunidades e ameaças, também pessoais e profissionais, que podem ocorrer conforme os pontos fortes e fracos previamente identificados. É a análise SWOT, uma análise das forças, fraquezas, oportunidades e ameaças de um objecto ou situação (ANSOFF, 1983).

O passo seguinte é avaliar quais os públicos envolvidos no planeamento (conhecido na literatura pelos stakeholders). De acordo com Freeman (1984), stakeholder pode ser definido como qualquer indivíduo, ou grupo de indivíduos, que é afectado pela empresa (por analogia deste caso aqui descrito, a empresa é o indivíduo) ou que afecta o alcance dos objectivos da empresa. Desta forma, cabe a pessoa analisar quem são estes stakeholders, o que eles querem, como eles reagirão e influenciarão no alcance dos seus objectivos. Exemplos de stakeholders 
dos indivíduos: marido ou esposa, filhos, pais, outros familiares, chefe, subordinados, colegas de trabalho, funcionários, clientes, fornecedores, amigos pessoais, instituições envolvidas (banca), entre outros. Estes stakeholders podem ajudar ou mesmo dificultar o alcance dos objectivos traçados pelo indivíduo. Segundo Sender e Fleck (2004), o sucesso da organização pode estar associado ao relacionamento com estes stakeholders (mais uma vez, faz-se a analogia da organização com o indivíduo); e, para Frooman (1999) é necessário identificar quem são os seus stakeholders, o que (e como) eles pretendem obter da instituição (objectivos); e é fundamental avaliar o impacto de cada stakeholder na vida da pessoa.

Respondidas estas questões, o indivíduo pode tomar decisões mais eficazes e com maior benefício (GREGORY, 2000).

O passo seguinte é uma análise de concorrentes. Quem concorre com a pessoa? 0 indivíduo é competitivo, tanto pessoal quanto profissionalmente? Neste caso, é importante analisar, por exemplo, a procura e a oferta de profissionais da área de formação do indivíduo, as possibilidades de que sua profissão seja substituída por outra (como foi o caso de operadores de telex ou mesmo dactilógrafos), competição entre colegas de trabalho, entre outros. É preciso estar ciente de quem pode tomar seu espaço para poder se defender ou mesmo ocupar o espaço de outros.

Para finalizar o diagnóstico, é necessário e muito importante a avaliar os recursos e capacidades da pessoa. Os recursos são os financeiros, recursos humanos (competências e habilidades), estruturas físicas (automóvel, casa, outros bens), recursos tecnológicos (conhecimento e tecnologia), e os organizacionais, que requerem uma coordenação; capacidade é a habilidade de coordenar um conjunto de recursos para a execução de tarefas ou actividades (GRANT, 1996). As capacidades aliadas aos recursos originam a vantagem competitiva, descrita por Porter (1985). Dentre os recursos e capacidades, é preciso listar o que está disponível, o que é fraco, o que é escasso, o que está ausente e seria necessário, etc.

Uma boa análise de recursos e capacidades pode direccionar para uma determinada estratégia, utilizando-se o que se tem de melhor e minimizando-se o que for escasso ou ausente. Avalia-se também a possibilidade de adquirir um recurso ou capacidade que seja importante porém esteja ausente (BARNEY, 1991). Por exemplo, competências com outras línguas ou em vendas e comunicação, podem ser adquiridas em cursos e com algumas práticas.

Tendo concluído o diagnóstico, o passo seguinte é a formulação da estratégia. Este caso depende de cada situação em especial. Primeiro, define-se os objectivos pessoais e profissionais. Devem ser objectivos de curto, médio e longo prazo. Algo como um rendimento desejado, um determinado automóvel, uma reforma sem preocupações, um ou mais imóveis, férias no exterior, um cargo na empresa, etc. Definidos os objectivos, o passo seguinte é escolher o caminho a trilhar: um planeamento de carreira profissional, a abertura de uma empresa após determinado tempo, uma poupança mensal, uma mudança de cidade ou país, a quantidade de filhos, o momento de casar (se isto for possível definir), entre outros. As estratégias pessoais são muitas e cada um escolhe uma ou mais estratégias conforme o diagnóstico realizado. Neste momento, a exactidão e credibilidade do diagnóstico será fundamental para a escolha de uma determinada estratégia pois dependerá dos seus objectivos e prazos. Por exemplo, se no diagnóstico for identificada a necessidade de adquirir um carro, e o objectivo específico é para realização de um sonho, a estratégia será coerente com a capacidade de pagamento do veículo. Entretanto se for um táxi, a estratégia poderá 
viabilizar sua compra com o próprio trabalho.

Para concluir a etapa da estratégia pessoal, segue-se a implementação, que é bem menos complexa do que nas organizações, por envolver somente o próprio indivíduo e as pessoas mais próximas a ele. Deve-se estabelecer metas e cronogramas a cumprir, de preferência por período para ter-se um pouco de flexibilização. Finalmente, faz-se o acompanhamento da estratégia. 0 controlo é importante para definir mudanças de rumos e prevenir possíveis problemas. Ajustes na estratégia, nas metas, nos cronogramas são fundamentais para se atingir os objectivos pretendidos.

\section{MARKETING PESSOAL}

A origem da palavra é anglo-saxónica, porém derivou do latim, mercari; foi utilizada para expressar acção voltada para o mercado (SHETH; GARDNER; GARRET, 1988), não existindo uma tradução para o português (COBRA, 2002).

0 marketing identifica necessidades e desejos insatisfeitos (KOTLER, 2005). Segundo Kotler e Keller (2005), inicialmente o marketing estava voltado para a perspectiva interna; visa criar, comunicar, entregar e trocar ofertas de valor para os públicos envolvidos. Com o passar do tempo. evoluiu para a interacção com o ambiente, diversificou-se e actualmente abrange um amplo campo de actuação, como o marketing político, o marketing ambiental, o marketing público, o marketing social, o marketing de relacionamento, entre outros (LEITE; NUNES, 2003).

Uma das mais novas áreas do marketing é o marketing pessoal. Segundo Peters (2000), o marketing pessoal utiliza dos conceitos e os instrumentos do marketing em benefício do indivíduo, sob o aspecto pessoal ou profissional, valorizando suas vantagens competitivas e direccionando seus processos, a fim de facilitar o melhor posicionamento no mercado. Destaca-se sua aplicação como uma ferramenta estratégica de promoção pessoal.

O marketing pessoal é então o marketing aplicado ao indivíduo e visa estabelecer caminhos que garantam retorno compatível com seus esforços despendidos, sendo o produto em questão (pessoa) a única diferença no planeamento e modelagem (PETERS, 2000).

Para Bidart (2001), o marketing pessoal aplica o composto de marketing para gerar interesse, atenção e preferência com relação a uma determinada pessoa. Usualmente é adaptado por artistas, desportistas, políticos e outros profissionais, pois a actividade exige grande projecção e reconhecimento popular, ou por pessoas com interesse pessoal em tornar-se uma celebridade. Entretanto, o marketing pessoal pode ser útil para qualquer pessoa que pretenda prosperar, e não necessariamente estar voltado para a "fama".

A aplicação do marketing pessoal no plano de vida proposto, envolve posicionamento ligado à própria pessoa, nomeadamente imagem e relacionamentos. A imagem é composta pela apresentação da pessoa, aliada à sua postura e capacidade de comunicação. A apresentação é o modo de apresentar-se na sociedade em termos visuais: roupas e acessórios que utiliza.

Apesar do objectivo ser não julgar as pessoas pela sua apresentação, consciente ou inconscientemente, todos acabam por fazê-lo. 0 modo como cada pessoa se mostra visualmente influencia como as outras pessoas irão tratá-la. A apresentação deve ser então um dos primeiros cuidados que um indivíduo precisa de ter quando visa prosperar, ao traçar 
seu plano de vida. Reflectir sobre seu visual e a adequação aos objectivos torna-se fundamental.

Junto com a apresentação vem a postura, que também é visual e mostra um pouco da personalidade da pessoa. Indivíduos que querem crescer, pessoal e profissionalmente, devem ter uma postura adequada às suas aspirações.

Por outro lado, nada adianta ter uma boa apresentação e postura se a pessoa não se consegue expressar. Falar bem é primordial na actualidade. Uma pessoa se expressa com dificuldade ou se expressa de uma forma inadequada terá dificuldades em criar relacionamentos úteis e importantes para o seu crescimento pessoal e profissional. Dominar a língua e suas nuances, saber falar individualmente ou em público, e expressar-se nos momentos certos e de forma adequada, são pontos-chave para os contactos com outras pessoas. Estas têm que entender o que o indivíduo quer comunicar, para se tornar respeitada. Isto não significa utilizar palavras pouco conhecidas, ou falar demasiado. Ao contrário uma boa comunicação considera o público para quem comunica, utiliza palavras adequadas e de fácil compreensão, tornando-se convincente.

No plano de vida proposto é importante uma análise detalhada da imagem da pessoa. Saber se está adequada ou precisa de ajustes é fundamental. E a apresentação, aliada a postura e comunicação, pode facilitar ou dificultar os relacionamentos (RIBEIRO, 1993). Esta análise da imagem contribui para o passo seguinte do plano, que é a rede de relacionamentos.

O ser humano é um ser social, portanto relaciona-se com seus semelhantes com grande frequência. Neste sentido, um ponto fundamental ao marketing pessoal é a capacidade de um indivíduo construir e manter relacionamentos, pessoais e profissionais. A rede de relacionamentos de uma pessoa costuma oferecer muitos benefícios: gera negócios, possibilita ou facilita a troca de informações ou mesmo a conquista de um novo emprego, mantém a pessoa ligada a um ou mais círculos sociais, entre outros. Uma boa rede de relacionamento contribui para a segurança e crescimento pessoal e profissional de um indivíduo.

Sendo assim, um ponto importante na análise do marketing da pessoa é avaliar sua rede de relacionamentos. Esta rede de relacionamentos pode surgir em ambientes como no trabalho, com clientes e fornecedores, no clube, no desporto, na escola, na igreja, em diversos locais. Conhecer pessoas é algo importante para o indivíduo. Sem uma boa rede de relacionamentos, a pessoa pode ficar sem ter a quem recorrer nos momentos difíceis.

Com as duas análises disponíveis, imagem e rede de relacionamentos, a sugestão neste momento é encontrar os pontos fortes e fracos, reconhecer o que precisa ser mantido e o que precisa ser alterado, estabelecer metas e alternativas de acções para que a pessoa possa garantir bons resultados.

Estabelecidas as metas, o passo seguinte é definir planos de acção. Estes planos devem contemplar as metas estabelecidas e as acções a desenvolver para atingi-las. Por exemplo, cursos que melhorem a comunicação da pessoa, frequentar determinados ambientes, etc. Este plano de acção deve estabelecer um cronograma de datas para definir o tempo disponível para atingir seus objectivos. Aliado ao cronograma, uma sugestão é estabelecer indicadores de avaliação do plano proposto. É preciso verificar sistematicamente o progresso em relação às metas traçadas. Por fim, estabelecer mecanismos de controlo que permitam realizar ajustes no plano de acção definido. 


\section{DESENVOLVIMENTO PESSOAL E PROFISSIONAL}

Para Zabalza (2004), o desenvolvimento pessoal está ligado ao processo de crescimento e à aquisição de capacidades pessoais, que facilite a integração na sociedade. De acordo com Pires (1995), o conceito de desenvolvimento pessoal refere a vivência de uma actividade contínua entre a pessoa e outros indivíduos, o estabelecimento de relações interpessoais com seu ambiente, os sentimentos por eles determinados e a noção do seu papel na sociedade. Depende directamente da qualidade das relações estabelecidas com o ambiente.

Já o desenvolvimento profissional é identificado como a aquisição de competências específicas ligadas ao mundo do trabalho e é entendido como o resultado de um processo de aquisição de competências e habilidades que envolve a socialização profissional, as suas interacções com seu meio profissional, a sua adaptação ao grupo profissional e suas perspectivas de carreira (MIZUKAMI, 1996).

Entre os mais prováveis benefícios da utilização de um plano de desenvolvimento pessoal e profissional, segundo Bennett (2006), destaca-se a motivação e confiança da própria aprendizagem, eficiência e eficácia dos objectivos de aprendizagem, com métodos mais adequados e ajustes às necessidades e interesses. As eventuais limitações destes planos estão associadas às incertezas, à interferência de outras pessoas, e à necessidade de apoios, financeiros e pessoais. Entretanto é difícil imaginar que o melhor para os indivíduos sejam experiências aleatórias e sem planeamento.

O desenvolvimento pessoal mostra-se fundamental para que se tenha uma boa qualidade de vida durante todas as fases de sua vida. Este desenvolvimento envolve, não somente a constituição de uma família, mas também as relações com seu meio social, bem como seus cuidados com sua saúde física e mental e tem por finalidade aumentar as expectativas de vida de cada sujeito.

Dentro da proposta do plano de vida ressalta-se uma reflexão acertada sobre a forma de condução da pessoa a respeito da sua vida pessoal, e que pode contribuir significativamente para atingir seus objectivos. Cuidados com sua saúde, com a família, formação e manutenção do seu círculo social pode ampliar ou reduzir a probabilidade de sucesso.

Para um plano de vida pessoal a proposta envolve uma reflexão da análise "SWOT pessoal" respondendo às seguintes questões: quais são suas forças e fraquezas a nível pessoal? Que competências e habilidades foram desenvolvidas e quais são os pontos fortes? Quais pontos ainda estão por desenvolver? Que cuidados a pessoa deve ter para desenvolver-se pessoalmente e profissionalmente? Que caminho trilhar? Como agir?

Exemplos de desenvolvimento pessoal não faltam: cuidados com a alimentação e com a saúde; realização frequente de exercícios físicos; vida social adequada e bem equilibrada; controlo nas aquisições e preocupação com o consumismo; relacionamentos com grupos sociais; existência e tamanho dos grupos de amigos; entre outros. 0 desenvolvimento da pessoa depende dela mesma, que precisa ter consciência da sua situação real para poder agir em benefício próprio e de forma contínua.

Já o desenvolvimento profissional influencia muito o desenvolvimento pessoal, e merece uma atenção cuidada por ser a forma de obtenção de recursos financeiros para atingir seus objectivos. Entre os benefícios da utilização de PDP (Plano de Desenvolvimento Profissional), resultado das investigações de Bennett (2006), encontram-se: 
- Aprendizagem relevante e desenvolvimento: é mais provável que aconteça quando dirigida para o objectivo;

- Aprendizagem planeada é mais eficiente;

- Oportunidades imprevistas de aprendizagem estão mais propensas a serem identificadas quando a pessoa está atenta a estas oportunidades;

- As opções de métodos de aprendizagem são mais apropriadas após a conclusão de um PDP;

- E a sua utilização pode ser concebidas e geridas para fornecer um ajuste sob medida com as necessidades e interesses do indivíduo;

- Motivação e confiança em assumir a responsabilidades pela própria aprendizagem podem ser ampliadas com o auxílio de um PDP.

As limitações dos PDP encontradas nas pesquisas, estão voltadas para a qualidade de um PDP, dificuldades na implementação e a validade do planeamento. Apesar dos perigos potenciais na utilização de PDP, é difícil imaginar que a aprendizagem através de experiências aleatórias possa ser o melhor caminho para os indivíduos e suas organizações.

Uma primeira análise é do caminho que já foi traçado até o momento pelo indivíduo. Como foi? Está seguindo em uma boa velocidade? Rápido demais? Lento demais? As escolhas profissionais podem facilitar ou mesmo dificultar o cumprimento dos objectivos pessoais traçados inicialmente. Considerando a análise histórica da carreira profissional da pessoa até o momento, é preciso identificar os principais pontos fortes e fracos do indivíduo como profissional. Além disto, também faz-se necessária uma avaliação ampla da profissão do sujeito para identificar oportunidades potenciais e possíveis ameaças, e envolve possibilidades de crescimento ou declínio da profissão em questão, empresas que utilizam os serviços destes profissionais, estabelecem rendimentos mínimos e máximos, cargos que pode vir a alcançar, entre outros.

Após esta análise prévia há um levantamento importante: das competências e habilidades. Que competências e habilidades o profissional possui? Estas competências ou habilidades identificadas são comuns aos outros profissionais ou são raras? 0 mercado de trabalho considera importante ter estas habilidades ou competências? Questões deste gênero ajudam a elucidar e reflectir sobre sua vida profissional, o que contribui para a compreensão do que considera-se forças e do que é preciso melhorar. Tendo consciência disto, pode buscar formações específicas que desenvolvam as competências e habilidades necessárias para sua profissão, transformando-as em vantagem competitiva profissional.

Tendo concluído estas análises de sua vida profissional, chega o momento de planear. E começa com o estabelecimento de metas e directrizes a seguir. Saber onde se quer chegar é necessário para elencar as diferentes opções, entre elas a troca de emprego ou mesmo a abertura da própria empresa. Finaliza-se esta etapa com o desenvolvimento e implementação de planos de acção para cumprir as metas estabelecidas, que vão contribuir para o atingir os objectivos do plano de vida.

\section{ENQUADRAMENTO LEGAL}

Sem a pretensão de tratar das questões legais que envolvam a reforma, pois para isso existem 
leis, o objectivo desta etapa diz respeito à organização da própria pessoa quanto aos aspectos legais que envolvam sua reforma, bem como os que influenciem o plano de vida traçado pelo indivíduo.

Três pontos tornam-se importantes ao se tratar do enquadramento legal quanto a reforma: a legislação que rege a reforma de cada profissão, as opções que uma pessoa tenha para se reformar, e os documentos necessários para possibilitar a reforma sem maiores problemas.

No que refere à legislação específica para a reforma, a orientação no plano de vida é buscar informações antecipadamente, quais as leis que regem a reforma da pessoa, especificamente na sua profissão e situação peculiar, seja empregado ou empreendedor. Sem conhecer seus direitos e deveres, pode-se ter alguns dissabores ao solicitar a reforma, e decepcionar-se com o resultado. Conhecer antecipadamente a legislação pode evitar problemas futuros e auxiliar o indivíduo na preparação para a sua vida, quando deixar de trabalhar.

Entre estes conhecimentos, destaque para as opções de reforma. Após anos de contribuições, será que a reforma garantida por Lei pelo Governo será suficiente? Ou será necessário contribuir também para uma Previdência Privada? Qual é a mais segura e adequada (segurança é a palavra chave, pois está-se a falar de investimentos numa instituição que deverá manter-se firme daqui a 20 ou 30 anos, quando muitas deixam de existir em breve espaço de tempo)? Será que atenderá às necessidades prévias da pessoa?

Uma escolha antecipada permite o planeamento e contribui para direccionar as acções de acordo com o interesse, por exemplo, o momento certo de contratar uma previdência privada, a hora de trocar de emprego, entre outros.

Finalmente, quanto aos aspectos legais, sempre surgem questões sobre quais documentos e comprovantes fazem parte do processo de solicitação de reforma. Cabe à pessoa, ao formular seu plano de vida, antecipar-se sobre a documentação necessária para evitar atrasos no momento da reforma.

Estas sugestões devem fazer parte do plano de vida que aliada à boa organização dos documentos e um conhecimento da legislação, facilita a tão esperada reforma.

\section{FINANÇAS PESSOAIS E INVESTIMENTOS}

Desenvolver um plano financeiro é escrever como atingir os objectivos, tendo a sua importância centrada na viabilização dos objectivos (TELÓ, 2001).

Para Gitman (1997), o planeamento financeiro pessoal, também conhecido como gestão em finanças pessoais, é um conjunto de ferramentas, baseado em modelos de processos flexíveis e adaptáveis, que proporcionam às pessoas e às famílias, os elementos essenciais para definir uma postura específica de relacionamento com o dinheiro. É um processo racional de gerir o rendimento, os investimentos, as despesas, o património, as dívidas, etc. 0 objectivo é tornar os sonhos, desejos e objectivos em realidade (casa, automóvel, casa de férias, viagens, reforma tranquila, entre outros).

0 planeamento financeiro pessoal deve seguir uma estratégia previamente definida (fase 1 do plano de vida), visando a acumulação de bens e valores, património de uma pessoa e da sua família. Essa estratégia depende de acções de curto, médio e longo prazo. Porém, esta não é uma tarefa simples de atingir, devido aos inúmeros imprevistos e incertezas da vida; 
actualmente, poucos indivíduos conseguem alcançar o objectivo financeiro principal: a completa tranquilidade económico-financeira.

Para a elaboração de um planeamento financeiro pessoal é necessário disciplinar as pessoas envolvidas directamente no projecto, a fim de concretizar os objectivos preestabelecidos e todas as etapas do plano. 0 sucesso de um plano financeiro depende muito das decisões tomadas. Definir antecipadamente o que espera alcançar, programar revisões periódicas para ajustar suas projecções, e como redefinir objectivos de curto, médio e longo prazo são essenciais no plano de vida, particularmente no âmbito financeiro.

O plano financeiro deve ser a ligação e conclusão de todo o planeamento desenvolvido no plano de vida pois, através deste, viabiliza-se todas as acções definidas nas etapas anteriores. Como já citado, planear as finanças pessoais é basicamente uma consequência da estratégia escolhida, bem como das acções de marketing, desenvolvimento pessoal e profissional e de aspectos relacionados ao enquadramento legal da reforma.

O planeamento financeiro é definido pelas outras etapas do plano porém será também a sua base de sustentação dos recursos para as acções até a esperada reforma, tranquila e feliz.

Quanto ao plano financeiro específico, inicialmente estabelece-se um diagnóstico financeiro da realidade actual da pessoa, seguido de um orçamento familiar, prevendo receitas e despesas futuras. A partir destas previsões consegue-se visualizar um fluxo do dinheiro para um determinado período. No acompanhamento semanal, mensalmente ou anual, consegue-se identificar desvios do plano pré-estabelecido. Cada desvio deve ser corrigido no fluxo de caixa e nas acções da pessoa ou dos envolvidos directamente no plano financeiro. Este tipo de acção evita uma das piores situações para o ser humano: uma crise financeira, que pode chegar a ter contornos trágicos.

Uma etapa importante do planeamento financeiro é referenciar investimentos e endividamentos, cuidadosamente planeados, para evitar surpresas e falta de recursos. Cada pessoa tem um perfil de investimento e de endividamento; alguns querem segurança enquanto outros querem rentabilidade. As opções podem variar entre imóveis, renda fixa, acções, etc.

Há que respeitar o perfil de cada indivíduo, pois deste perfil nascem as suas expectativas. Fazse necessária uma distinção muito importante, entre o que é investimento e o que é despesa. Um carro, normalmente considerada uma despesa, se for fundamental 'para desenvolver uma actividade pode ser considerado um investimento, pois sem ele não se desenvolve o trabalho. Assim, despesa é um gasto, normalmente motivado por um desejo, enquanto do investimento espera-se um retorno (GITMAN, 1997).

Por fim, uma análise de risco, aliada ao perfil de investidor, é fundamental para desenvolver o planeamento financeiro e exige uma análise mais apurada, evitando o excesso de optimismo em seus planos, e considerando que riscos estão dispostos a ocorrer. Riscos como problemas de saúde, acidentes, roubos, perda do emprego, problemas de mercado (para os empreendedores) são muito mais comuns do que se possa imaginar. Entretanto, as pessoas pensam que só acontece com os outros. A sugestão é considerar que riscos podem acontecer (como um terramoto, por exemplo) e o que fazer para solucionar, se viesse a concretizar-se.

Pode estabelecer uma expectativa de que cada um dos riscos aconteça, e assim planear com algum sucesso. 
O objectivo desta etapa foi somente reforçar a necessidade de se realizar investimentos, sempre que possível, e evitar endividamentos desnecessários (como cartão de crédito, ou empréstimos para viagens de férias). Como consequência da análise dos riscos, é preciso desenvolver os planos de contingência, ou planos de emergência, que tentam orientar em situações de crise. Cada risco analisado gera um plano de contingência ou uma solução, pensada racionalmente quando ainda não se está na situação de crise.

\section{MODELO PROPOSTO - ETAPAS DO PLANO DE VIDA}

Partindo-se dos modelos mais comuns de desenvolvimento de um plano de negócios, um resumo da proposta para o plano de vida é apresentado no quadro 1 . No projecto aqui descrito, cada etapa foi detalhada, constituindo-se, no final do estudo, um guia para o planeamento de vida de uma pessoa.

Quadro 1: Modelo Proposto para Plano de Vida

\begin{tabular}{|c|c|}
\hline Etapa & Descrição \\
\hline $\begin{array}{l}\text { Etapa } 1 \\
\text { Estratégias Pessoais }\end{array}$ & $\begin{array}{l}\text { - Fase } 1 \text { - Diagnóstico: } \\
\text { - SWOT pessoal e profissional; } \\
\text { - Stakeholders envolvidos; } \\
\text { - Análise de competitividade pessoal e profissional; } \\
\text { - Avaliação de recursos (disponíveis, fracos, escassos, ausentes); } \\
\text { - Avaliação de capacidades (disponíveis, escassas, ausentes); } \\
\text { - Fase } 2 \text { - Formulação Estratégica: } \\
\text { - Definição de objectivos pessoais e profissionais; } \\
\text { - Escolha de estratégias pessoais e profissionais; } \\
\text { - Fase } 3 \text { - Implementação da(s) Estratégia(s); } \\
\text { - Fase } 4 \text { - Controlo Estratégico; }\end{array}$ \\
\hline $\begin{array}{l}\text { Etapa } 2 \\
\text { Marketing }\end{array}$ & $\begin{array}{l}\text { - } \quad \text { Marketing Pessoal: } \\
\text { - } \quad \text { Avaliação da imagem pessoal; } \\
\text { - } \quad \text { Avaliação da rede de contactos; } \\
\text { - } \quad \text { Definição de metas e alternativas de acção; } \\
\text { - } \quad \text { Plano(s) de acção(s); } \\
\text { - } \quad \text { Indicadores de avaliação; } \\
\text { - } \quad \text { Controlos; }\end{array}$ \\
\hline $\begin{array}{l}\text { Etapa } 3 \\
\text { Desenvolvimento Pessoal }\end{array}$ & $\begin{array}{ll}\text { - } & \text { Forças Pessoais; } \\
\text { - } & \text { Fraquezas Pessoais; } \\
\text { - } & \text { Competências e Habilidades Desenvolvidas; } \\
\text { - } & \text { Competências e Habilidades a Desenvolver; } \\
\text { - } & \text { Cuidados Necessários; } \\
\text { - } & \text { Directrizes a Seguir; } \\
\text { - } & \text { Plano(s) de Acção(s); }\end{array}$ \\
\hline $\begin{array}{l}\text { Etapa } 4 \\
\text { Desenvolvimento } \\
\text { Profissional }\end{array}$ & $\begin{array}{ll}\text { - } & \text { Forças Profissionais; } \\
\text { - } & \text { Fraquezas Profissionais; } \\
\text { - } & \text { Oportunidades de Carreira; } \\
\text { - } & \text { Ameaças à Carreira; } \\
\text { - } & \text { Competências e Habilidades Desenvolvidas; } \\
\text { - } & \text { Competências e Habilidades a Desenvolver; } \\
\text { - } & \text { Definição de Metas e Directrizes; } \\
\text { - } & \text { Estabelecimento de Opções; } \\
\text { - } & \text { Plano(s) de Acção(s); } \\
\text { - } & \text { Planos Alternativos; }\end{array}$ \\
\hline
\end{tabular}




\begin{tabular}{|c|c|}
\hline $\begin{array}{l}\text { Etapa } 5 \\
\text { Enquadramento Legal }\end{array}$ & $\begin{array}{ll}\text { - } & \text { Legislação da Reforma; } \\
\text { - } & \text { Opções de Reforma; } \\
\text { - } & \text { Questões Documentais; }\end{array}$ \\
\hline $\begin{array}{l}\text { Etapa } 6 \\
\text { Finanças Pessoais e } \\
\text { Investimentos }\end{array}$ & $\begin{array}{ll}\text { - } & \text { Situação Financeira Actual; } \\
\text { - } & \text { Previsões de Receitas; } \\
\text { - } & \text { Previsões de Despesas; } \\
\text { - } & \text { Fluxo de Caixa Orçamentado; } \\
\text { - } & \text { Alternativas de Investimentos; } \\
\text { - } & \text { Riscos Potenciais; } \\
\text { - } & \text { Plano(s) de Contingência(s). }\end{array}$ \\
\hline
\end{tabular}

Fonte: Elaboração Própria

É importante ressaltar que este plano é um conjunto de orientações para o indivíduo atingir seus objectivos. Não garante o sucesso, mas ajuda as pessoas a chegarem lá.

\section{CONSIDERAÇÕES FINAIS}

Sendo a reforma um momento crítico na vida de cada pessoa, o objectivo deste estudo foi propor um "plano de vida", um guia de planeamento pessoal que visa uma reforma tranquila, e que tomou por base os modelos tradicionais de planos de negócios. Este plano de vida compõe-se de seis etapas: estratégias pessoais, marketing pessoal, desenvolvimento pessoal, desenvolvimento profissional, enquadramento legal, e finanças pessoais e investimentos. Cada etapa do plano proposto foi apresentado para que os interessados em se prepararem para a reforma tenham um guia para o seu plano pessoal.

Realizar um planeamento pessoal não é uma tarefa fácil. Muitas pessoas gostariam de traçar seus caminhos até sua reforma, mas não o sabem como fazer. Neste estudo, buscou-se esclarecer isto e demonstrar que a realização de um plano de vida não é tão complexo quanto se imagina. Ao contrário, a parte mais fácil é o desenvolvimento do plano. 0 mais difícil, sem dúvida, é seguir o que foi previamente definido. Exige disciplina, controlo, razão.

Mas tudo isto pode ser conseguido. Basta dar o primeiro passo. E este passo inicial pode ser a descrição formal dos objectivos e caminhos a trilhar pessoalmente. Tendo definindo-se um rumo, fica mais fácil ver os objectivos a serem alcançados.

Por fim, este trabalho apresenta-se como uma versão inicial do desenvolvimento de um plano de vida completo. É preciso testá-lo na prática e um caminho para isto é o desenvolvimento de softwares específicos para o desenho do plano, possivelmente o segundo passo para tornar o plano de vida algo ao alcance das pessoas que se preocupam com sua reforma.

Neste sentido, as organizações que estão envolvidas com a reforma dos cidadãos podem contribuir significativamente. Oferecer uma previdência privada acompanhada de um plano de vida pode ser um meio de conquistar mais clientes, bem como manter a base de clientes actuais.

Uma instituição que gere os recursos depositados pelos seus clientes visando a reforma, deve acompanhar toda a vida de cada cliente. No acto da contratação do serviço, o desenvolvimento do plano de vida pode ajudar aos contratantes nos passos a dar até a reforma. Mas não basta formalizar o planeamento pessoal de cada indivíduo. É preciso acompanhar estes clientes. 0 que se encontra actualmente é que, após a contratação da previdência privada, a instituição que faz a gestão destes fundos pouco contacta os clientes. 
Quando o faz normalmente está associado à falta de pagamento ou para tentar demovê-lo da ideia de levantar os fundos depositados.

Com o plano de vida, a instituição cria uma relação mais constante com o cliente, prevendo potenciais desistentes e auxilia-os a não desistir. Uma sugestão é a instituição reunir-se uma vez ao ano com cada cliente para uma revisão do plano de vida. Isto aproxima a instituição de seus clientes e perpetua as relações entre ambos. É uma sugestão que pode ser útil para as organizações do sector.

\section{REFERÊNCIAS}

ABRAMS, R. Plano de negócios: segredos e estratégias para o sucesso. São Paulo: Érica, 1994.

ALBERTO, L. Os determinantes da felicidade no trabalho: um estudo sobre a diversidade nas trajetórias profissionais de engenheiros. 322f. Dissertação de Mestrado em Psicologia, Instituto de Psicologia da USP, Universidade de São Paulo, São Paulo, 2000.

ANSOFF, H. Administração estratégica. São Paulo: Atlas, 1983.

ARKEBAUER, J. Guide to writing a high-impact business plan: a proven blueprint for entrepreneurs. New York: The McGraw-Hill, 1994.

BANCO MUNDIAL. Poverty reduction and growth: virtous and vicious circles. Washington: Banco Mundial, 2006.

BARNEY, J. "Firm resource and sustained competitive advantage", Journal of Management, Vol. 17, pp. 99-120, 1991.

BENNETT, B. "Personal development plans: evidence from research on their use", Development and Learning in Organizations, Vol. 20, nº 6, pp. 13-15, 2006.

BIDART, L. Marketing pessoal: você sabe o que é? São Paulo: Gryphus, 2001.

BRACKER, J. "The historical development of the strategic management concept", The Academy of Management Review, Vol. 5, n² 2, Abril, pp. 219-224, 1980.

CAMARGOS, M.; DIAS, A. “Estratégia, administração estratégica e estratégia corporativa: uma síntese teórica", Caderno de Pesquisas em Administração, Vol. 10, n 1, pp. 27-39, 2003.

COBRA, M. "Um resumo do percurso do marketing brasileiro", Revista FAE BUSINESS, Vol. 4, Dezembro, pp. 28-32, 2002.

COLLIER, M. "Development of a business plan for an international co-operative digital library: the European Library (TEL)", Program: Electronic Library and Information Systems, Vol. $38, n^{\circ} 4$, pp. 225-231, 2004.

FLOODGATE, J.; NIXON, A. "Personal development plans: the challenge of implementation - a case study”, Journal of European Industrial Training, Vol. 18, n 11, pp. 43-47, 1994.

FRANKLIN, M. "Preserve tour savings for life", Kiplinger's Personal Finance Retirement Planning Guide, Washington, Outono, pp. 63-66, 2008. 
FREEMAN, R. "The politics of stakeholders theory: some future directions". In: DIENHART, J. (org.). Business Ethics Quarterly, Vol. 4, n 4, pp. 409-422, 1984.

FROOMAN, J. "Stakeholder influence strategies", Academy of Management Review, Vol. 24, $\mathrm{n}^{\circ} 2$, pp. 191-203, 1999.

GIACOBBO, E.; REIS, D.; FRANCISCO, A. “Estudo da viabilidade técnica e econômica (EVTE) e o plano de negócios como forma de avaliar o risco dos processos de inovação em pequenas e médias empresas". Simpósio de Gestão da Inovação Tecnológica, 23, Curitiba, 2004. Anais... Curitiba: XXIII Simpósio de Gestão da Inovação Tecnológica, 2004.

GITMAN, L. Princípios de administração financeira. São Paulo: Harbra, 1997.

GRANT, R. Dirección estratégica: conceptos, técnicas y aplicaciones. 1. ed. Madrid: Civitas, 1996.

GREGORY, R. "Using stakeholder values to make smarter environmental decisions", Environment, Vol. 42, $\mathrm{n}^{\circ}$ 5, pp. 34-44, 2000.

HIGSON, M.; WILSON, J. "Implementing personal development plans: a model for trainers, managers and supervisors", Industrial and Commercial Training, Vol. 27, n 6, pp. 25-29, 1995.

HORMOZI, A.; SUTTON, G.; MCMINN, R.; LUCIO, W. "Business plans for new or small businesses: paving the path to sucess", Management Decision, Vol. 40, ${ }^{\circ}$ 8, pp. 755-763, 2002.

KOTLER, P. 0 marketing sem segredos. Porto Alegre: Bookman, 2005.

KOTLER, P.; KELLER, K. Marketing management. 12 ed. New Jersey: Pearson- Prentice Hall, 2005.

LEITÃO, D. Administração estratégica: abordagem conceitual e atitudinal. Rio de Janeiro: SENAI/DN e Petrobrás, 1995.

LEITE, G.; NUNES, R. "A função social do marketing". Jornadas Hispano-Lusas de Gestión Científica, 13, Lugo/Espanha, 2003. Anais... Lugo/Espanha: XIII Jornadas Hispano - Lusas de Gestión Científica, 2003.

LONGENECKER, J.; MOORE, C.; PETRY, J. Administração de pequenas empresas. São Paulo: Makron Books, 1997.

LUNNARDI FILHO, L. "Prazer e sofrimento no trabalho: contribuições à organização do processo do trabalho da enfermagem", Revista Brasileira de Enfermagem. Vol. 50, n 1, pp. 77-92, 1997.

MAINARDES, E.; FERREIRA, J.; ANDRADE, S. "Concepts perception of strategy and strategic management: university case study”, Chinese Business Review, Vol. 7, n 1, pp. 35- 46, 2009.

MARTÍN-BARÓ, I. “Conflicto social e ideología científica: de Chile a El Salvador”. Congresso Interamericano de Psicologia, 20, Caracas, 1985. Anais... Caracas: XX CIP, 1985.

MARTINEZ, M.; PARAGUAY, A.; LATORRE, M. "Relação entre satisfação com aspectos psicossociais e saúde dos trabalhadores”, Revista de Saúde Pública, Vol. 38, n 1, pp. 55-61, 
2004.

MCCARTHY, D.; MINICHIELLO, R.; CURRAN, J. Business policy and strategy: concepts and readings. Homewood/Illinois: Irwin, 1975.

MINTZBERG, H. The strategy concept I: five P's for strategy", California Management Review, Outono, pp. 11-24, 1987.

MIZUKAMI, M. “Docência, trajetórias pessoais e desenvolvimento profissional”. In: Reali, A. e Mizukami, M. (org.). Formação de professores: tendências atuais. São Carlos: EDUFSCar, pp.59-91, 1996.

PETERS, T. Reinventando o trabalho. São Paulo: Campus, 2000.

PIRES, A. Desenvolvimento pessoal e profissional: um estudo dos contextos e processos de formação das novas competências profissionais. Dissertação de Mestrado em Ciências de Educação, Faculdade de Ciências e Tecnologia da Universidade Nova, Monte da Caparica, Lisboa, 1995.

PORTER, M. Competitive advantage: creating and sustaining competitive performance. New York: Free Press, 1985.

RIBEIRO, L. Comunicação global: a mágica da influência. Rio de Janeiro: Objetiva, 1993.

RODRIGUES, M.; AYABE, N. ; LUNARDELLI, M.; CANÊO, L. “A preparação para a aposentadoria: o papel do psicólogo frente a essa questão", Revista Brasileira de Orientação Profissional, Vol. 6, n 1, pp. 53-62, 2005.

RULE, R. The Rule book of business plan for statups. Oregon Point: The Oasis Press, 1999.

SCHNAARS, S. Marketing strategy: a customer-driven approach. New York : Free Press, 1991.

SENDER, G.; FLECK, D. "Folga organizacional e gestão de stakeholders: um estudo em bancos brasileiros". Encontro da ANPAD, 28, 2004, Curitiba. Anais... Curitiba: XXVIII EnANPAD, 2004.

SHARMA, P. The Harvard entrepreneurs club: guide to starting your business. Hoboken: John Wiley \& Sons Inc, 1999.

SHETH, J.; GARDNER, D.; GARRETT, D. Marketing theory: evolution and evaluation. New York: John Wiley \& Sons, 1988.

SIMIÃO, J. "Planejando uma vida profissional de sucesso", Revista FAE BUSINESS, Vol. 6, Agosto, pp. 42-44, 2003.

SIMÕES, C. Curso de direito do serviço social. São Paulo: Cortez, 2007.

STEINER, G.; MINER, J. Política e estratégia administrativa. Rio de Janeiro: Interciência, 1981.

TAMKIN, P. “Techniques: pratical applications for personal development plans”, Management Development Review, Vol. 9, nº 7, pp. 32-36, 1996. 
TAYLOR, D.; EDGE, D. "Personal development plans: unlocking the future", Career Development International, Vol. 2, n 1, pp. 21-23, 1997.

TELÓ, A. "Desempenho organizacional: planejamento financeiro em empresas familiares", Revista FAE BUSINESS, Vol. 4, pp. 21-26, 2001.

WARD, J. "Planejar para prosseguir", HSM Management, ${ }^{\circ} 41$, novembro-dezembro, pp. 2633, 2003.

ZABALZA, M. La enseñanza universitária: el escenario y sus protagonistas. Madrid: Narcea Ed, 2004.

ZANELLI, J.; SILVA, N. Programa de preparação para aposentadoria. Florianópolis-SC: Insular, 1996. 